\title{
Preliminary Study: A New Approach for Improving the Cryopreservation of Mammalian Sperm
}

\author{
Galit Hermann, Natalia Zabludovsky, Yosef Steinberger* \\ The Mina \& Everard Goodman Faculty of Life Sciences, Bar-Ilan University, Ramat-Gan, Israel \\ Email: *yosef.steinberger@biu.ac.il
}

How to cite this paper: Hermann, G., Zabludovsky, N. and Steinberger, Y. (2019) Preliminary Study: A New Approach for Improving the Cryopreservation of Mammalian Sperm. Open Journal of Animal Sciences, 9, 401-413.

https://doi.org/10.4236/ojas.2019.94032

\section{Received: July 16, 2019}

Accepted: September 15, 2019

Published: September 18, 2019

Copyright $\odot 2019$ by author(s) and Scientific Research Publishing Inc. This work is licensed under the Creative Commons Attribution International License (CC BY 4.0).

http://creativecommons.org/licenses/by/4.0/

\begin{abstract}
Gamete preservation is a necessary and routine procedure practiced in the 21 st century in both humans and animals using the cryopreservation technique. However, cryopreservation methods can cause cryoinjury. Therefore, new approaches to help extend the viability of mammalian sperm in vitro are essential. This preliminary study explored the effect of reproductive fluids (RFs) and body fluids (BFs) from two species of desert snails-Sphincterochila zonata and Sphincterochila prophetarum-on mammalian cryopreserved sperm parameters. These desert snails are active only $5 \%$ of the year. Spermatogenesis occurs during the aestivation ecophysiological stage when testosterone levels are high, and sperm is preserved in the oviduct until mating during the active ecophysiological stage in winter. RFs from $S$. zonata and $S$. prophetarum during the aestivation ecophysiological stage reduced sperm motility to $0 \%$, while sperm viability (SV) was similar to the controls. Moreover, the motility of thawed mouse sperm was 1.34 - and 2.02 -fold higher $(p<0.05)$ in RF medium obtained from $S$. zonata in the active ecophysiological stage than in the control medium after 5- and 30-min incubation. SV was higher in S. zonata RF medium than in control after $30 \mathrm{~min}$ incubation. Our results indicate the potential protective effect of desert snail RFs on cryopreserved and thawed mammalian sperm cells. Further study should be conducted to advance the fulfillment of RF potential in reproductive technologies.
\end{abstract}

\section{Keywords}

Desert snail, Fertility, Cryopreservation, Mammalian Sperm

\section{Introduction}

One of the most common gamete preservation-cryopreservation techniques is 
based on reducing the medium and sperm cell temperature. Such a procedure triggers a decrease in cell activity that prolongs cell life [1] [2] [3] and can fulfill the sperm biological functions, similar to a non-solidified cell unit. Animal gamete protection is a necessity and a routine procedure used in the 21 st century to prevent the extinction of organisms at different levels [4].

Cryopreservation methods are known to have negative effects on mammalian sperm-cell properties that can initiate cryoinjury effects [5] [6] [7], including changes in cell morphology caused by shrinkage or by the formation of intracellular ice. Such changes can result in macromolecule denaturation [8] [9], by damaging plasma and mitochondrial membranes [10], and by reducing sperm motility [10]. The demand for new methodologies and approaches to help extend the viability of mammalian sperm compared with previous cryopreservation processes is of great value.

Based on accumulated knowledge, activity, feeding behavior, and the reproductive cycle of desert snails [11] [12] [13], we have learned that desert snails fulfill their biological functions during a period of 22 to 25 days of the year in an unpredictable xeric environment. This feature has become our foremost objective, represented by the most common terrestrial gastropods, Sphincterochila zonata and Sphincterochila prophetarum, in the Negev Desert, Israel. [14] described the reproductive system of terrestrial and freshwater gastropods and their endocrinology regularity system, elucidating the changes in the steroid hormone testosterone ( $\mathrm{T}$ ) and $17 ß$ estradiol (E2). These hormones were found to encourage spermatogenesis and oogenesis in the slug Arion ater rufus [15] [16], in the terrestrial snail Euhadra peliomphala [17] [18], and in the neogastropod Ilyanassa obsolete [19]. In our previous study [11] of the levels of the steroid hormones T and E2 in $S$. zonata and $S$. prophetarum, we found fluctuations throughout the year according to their different aestivating and active ecophysiological stages in the northern Negev Desert.

These two desert snail species, known as hermaphrodites, have a distinct spermatogenic cycle that is influenced by their life cycle, which is strongly linked to the abiotic conditions. The snails are found in the exposed aestivation stage $90 \%$ of the year, i.e., throughout the dry spring, summer, autumn, and dry winter seasons [12] [13]. They become active approximately 5\% of the year, and during this short and fragmented time, they fulfill all their biological functions (e.g., feeding, growing, mating, and laying eggs). Their activity is restricted to the unpredictable periods of rainfall events. During the $90 \%$ of their inactive aestivation ecophysiological stage, the desert snails prepare sperm cells that are preserved in the seminal vesicle region of the hermaphrodite duct until fertilization, thus guaranteeing successful egg fertilization.

According to [20], the oogenesis stage occurs in the winter season, during the active stage. These findings are in line with our previous results [11] showing that high $\mathrm{T}$ levels during the aestivation stage and low $\mathrm{T}$ levels and high $\mathrm{E} 2$ levels during the active ecophysiological stage, in winter. $S$. zonata and $S$. prophetarum 
desert snails have been the subject of many studies investigating strategies for survival in an extreme and unpredictable environment [12] [13] [20] [21] [22] [23].

The integration of field observation and knowledge accumulated regarding the long-term maintenance of sperm viability (SV) in snail RF along an irregular period and the short-term mammalian SV without cryopreservation is an enigma. The unique idea is to investigate the influence of the desert snail BFs and RFs from different ecophysiological stages on thawed mouse sperm-cell parameters. The objective of this study was to determine the effect of the RFs of $S$. zonata and $S$. prophetarum from the aestivation and active ecophysiological stages on the survival of mouse sperm cells in vitro. We hypothesized that 1) the RFs obtained from the desert snails $S$. zonata and $S$. prophetarum during the active ecophysiological stage in the winter season will provide vital support that will facilitate sperm movement, and 2) the RFs obtained from $S$. zonata and $S$. prophetarum during the aestivation ecophysiological stage will reduce sperm motility without damaging their viability. Emphasis was placed on evaluating the $\mathrm{T}$ and $\mathrm{E} 2$, whose concentrations were at two different ecophysiological stages-the active stage in winter (since oogenesis occurs during this period, and individuals are active and mating), and the aestivation stage (when spermatogenesis takes place) (see methods).

\section{Materials and Methods}

\section{Collection of snails from the field}

Live specimens of snail species $S$. zonata and $S$. prophetarum (identified by Steinberger) were collected from the northern Negev Desert $\left(34^{\circ} 50 \_E / 30^{\circ} 50 \_\mathrm{N}\right)$ of Israel during winter (December) 2014, when snails were active, and in summer (August) 2014 during the aestivation ecophysiological stage. The collected snails were immediately placed in a bin containing solid carbon dioxide at $-20^{\circ} \mathrm{C}$ and transported to the laboratory. At the laboratory, they were individually marked, weighed, and preserved at $-20^{\circ} \mathrm{C}$ before steroid sex-hormone determination. Aestivation was defined as having a thick $\mathrm{CaCO}_{3}$ epiphragm covering the shell opening during the summer season.

\section{Laboratory analysis}

\section{Snail sex-hormone determination}

Before the determination of $\mathrm{T}$ and $\mathrm{E} 2$ levels, the soft tissue from each animal was removed from the shell. Due to the difference in size between the two species, T and E2 levels were determined in $S$. zonata individuals $(\mathrm{n}=5)$, while in $S$. prophetarum, to receive the necessary tissues that allowed detection $(n=6)$, tissues from two individual specimens were pooled, allowing us to obtain three replicates. The dry weight of the snails collected in the field was determined (mean value dry weight for $S$. zonata of 0.45 g/individual, $n=5$; vs. 0.14 for $S$. prophetarum, $n=5$ ). For $S$. zonata, the average dry weight ranged between 0.23 and $0.68 \mathrm{~g}$ dry wt for summer and winter, respectively, while for $S$. prophetarum, 
it ranged between 0.08 and $0.20 \mathrm{~g}$ dry wt for summer and winter, respectively.

The tissues were homogenized using a glass homogenizer. Two ml-distilled water added, and the tissues extracted twice with five volumes of ethyl acetate. The organic solvent extract was then evaporated in air till dry and redissolved in $2 \mathrm{ml} \mathrm{100 \%}$ methanol (Ultra-Resi-Analyzed, J.T. Baker, Phillipsburg, NJ). Aliquots (100 ųl) of methanol extract were taken, evaporated, and the residue redissolved in 100 ųl of steroid assay buffer. T and E2 analyzed using the Enzyme Immunoassays (EIA) kit (Cayman Chemicals, Ann Arbor, MI).

\section{Impact of snail fluid on mouse sperm cells \\ Snail preparation and dissection}

To examine the impact of $S$. zonata and $S$. prophetarum RFs and BFs during the aestivation and active ecophysiological periods on mammalian sperm cells, the following procedure used for both seasons. At the aestivation ecophysiological stage, $S$. zonata $(\mathrm{n}=4)$ and $S$. prophetarum $(\mathrm{n}=4)$ individuals were opened, and the soft mollusk body was removed with tweezers. The snails dissected, and the oviduct with the seminal vesicle was isolated and transferred into a sterilized test tube containing the RFs. Also, the soft body (without the leg since it was mostly muscle) tissues containing the BFs were pooled in a separate sterilized test tube. As a result, we harvested two fluids, RF and BF, for each snail species.

The tissues were resuspended with $500 \mu$ distilled, sterilized water to decrease fluid viscosity. The samples were centrifuged at $1500 \mathrm{rpm} \times 10 \mathrm{~min}\left(5^{\circ} \mathrm{C}\right)$, and the supernatant removed. The fluids were divided into two parts: one part was stored at $-20^{\circ} \mathrm{C}$, while the other part used for studying the mouse sperm cell viability and total motility in vitro. A similar method was used for RF and BF extraction from the winter season active ecophysiological stage of $S$. zonata ( $\mathrm{n}=$ 4 ) and $S$. prophetarum $(\mathrm{n}=4)$. During this season, we had only one control (not 2 , like in summer). At this period, the oviduct is well developed and visible via the soft body after removal of the shell (Figure 1). Moreover, egg formation was detected in the oviduct of $S$. zonata (Figure 2).

\section{Influence of snail fluids on mouse sperm cells}

At the aestivation ecophysiological stage, thawed semen from individual mice was used for two replications of spermiogram observation using snail aliquots. Semen from individual mice after cryopreservation (thawing of mouse semen was done at $37^{\circ} \mathrm{C}$ during $5 \mathrm{~min}$ in a water bath) added to different $S$. zonata and $S$. prophetarum BFs as follows: 1) control-thawed mouse semen; 2) control—thawed mouse semen with Ham's F10 medium 1:1 [24]; 3) thawed semen was added to RFs (1:1); and (4) thawed semen was added to BFs (1:1). At the active ecophysiological stage, cryopreserved mouse semen $(n=3)$ was added to different $S$. zonata and $S$. prophetarum BFs as follows: 1$)$ control thawed semen $(\mathrm{n}=2) ; 2)$ thawed semen added to BFs of $S$. zonata $(\mathrm{n}=3) ; 3)$ thawed semen was added to BFs of S. prophetarum $(n=9) ; 4)$ thawed semen was added to RFs of S. zonata $(\mathrm{n}=3)$; and 5) thawed semen was added to RFs of $S$. prophetarum $(\mathrm{n}=9)$. 


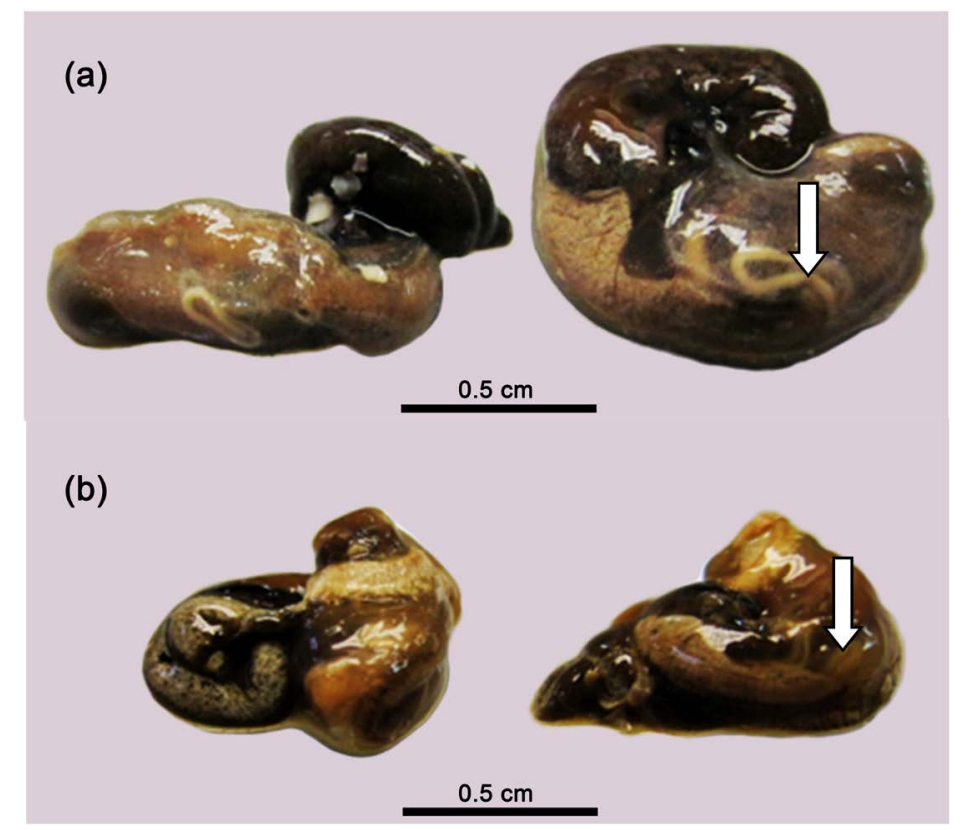

Figure 1. Two individual snail species after removing coiled shell of (a) Sphincterochila zonata and (b) S. prophetarum, winter 2014. Differences in body size can be seen; arrows show oviduct in vivo.

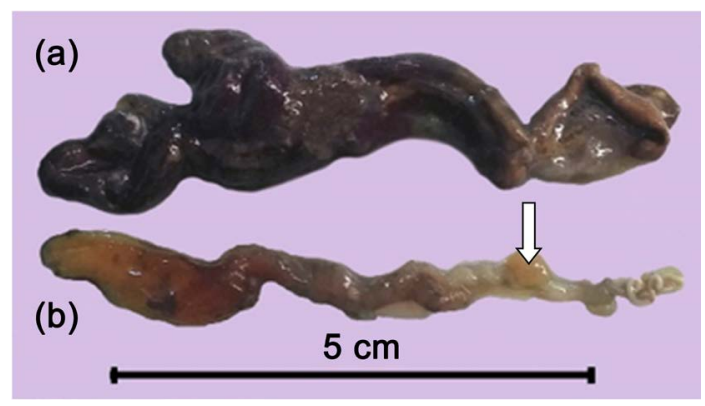

Figure 2. Sphincterochila zonata, dissected specimen: digestive system (a) and reproductive system (b); winter 2014.

\section{Mouse sperm cell evaluation \\ Sperm count after thawing}

The mouse sperm count was determined by hemocytometry (Neubauer chamber) using the method described in the World Health Organization manual (WHO, 2010). Ten microliters of sperm suspension transferred to a Neubauer chamber, and sperm cells counted.

\section{Sperm motility}

To observe motility, $10 \mu \mathrm{l}$ of semen suspension was placed on a glass slide and covered with a lamella. Using a light microscope with a magnification of $\times 40$, the numbers of sperm with progressive forward movement were counted in several microscopic fields (WHO, 2010). Finally, 100 spermatozoa detected to determine the percentage of motility.

Sperm viability $(S V)$

Viability of mouse sperm cells examined using the supravital staining method 
[25] [26]. An amount of $20 \mu \mathrm{l}$ spermatozoa was stirred (for $30 \mathrm{sec}$ at $37^{\circ} \mathrm{C}$ ) in $60-\mu$ eosin-nigrosin (E\&N) stain, i.e., 5\% nigrosin and 4\% eosin-Y at a ratio of 3:1. After that, smears were prepared, dried at room temperature, and examined with $\times 100$ oil magnification. Finally, 100 sperm cells were counted. Sperm cells with stained cytoplasm in the head were considered to be dead [25] and the results were expressed as the percentage of live sperm cells.

\section{Statistical analysis}

All data were subjected to statistical analysis of variance using the SAS model (ANOVA and Duncan's multiple range test and Pearson correlation coefficients) to evaluate differences between separate means. ANOVA was followed by Tukey's HSD (honest significant difference) test to establish the significance of differences between mouse sperm in the RF and BF of both snail species at different ecophysiological stages using the statistical package Statistica 4.3. Differences obtained at levels of $p<0.05$ were considered significant.

\section{Results}

\section{Sex-hormone analysis}

The levels of the sex hormones T and E2 in both snail species at the different ecophysiological stages in summer and winter are presented in Figure 3. The $\mathrm{T}$ levels during the aestivation stage in summer were found to be significantly higher $(\mathrm{p}<0.05)$ in comparison with the $\mathrm{T}$ levels during the active stage in winter. Concentrations of T in $S$. zonata were 11.67 and $1.53 \mathrm{ng} / \mathrm{g}$ dry wt in summer and winter 2014, respectively, and the T levels of S. prophetarum were two- and five-fold lower (5.34 and $0.37 \mathrm{ng} / \mathrm{g}$ dry wt, respectively), for the same periods. The E2 levels in the two snail species showed no significant $(p>0.05)$ differences between the active and aestivation periods (3.31 and $2.60 \mathrm{ng} / \mathrm{g}$ dry wt for $S . z o$ nata, and 3.52 and $2.61 \mathrm{ng} / \mathrm{g}$ dry wt. for $S$. prophetarum), respectively.

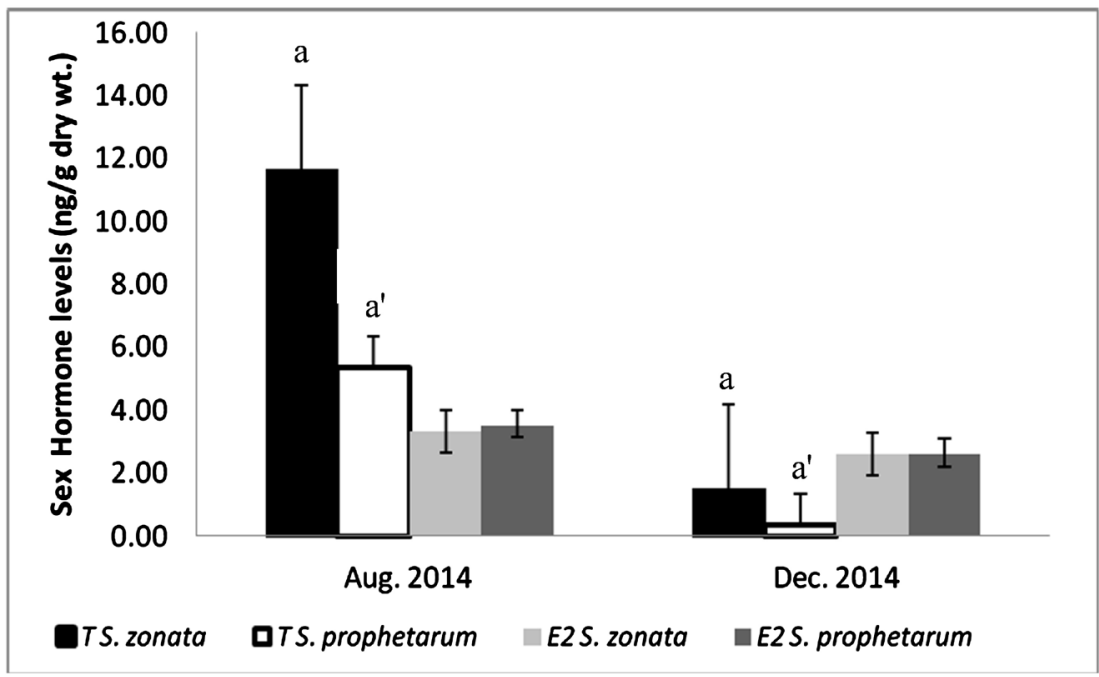

Figure 3. Mean values $( \pm \mathrm{SE})$ of the sex hormone levels of testosterone $(\mathrm{T})$ and estradiol (E2) in $S$. zonata and $S$. prophetarum in summer and winter $2014(\mathrm{n}=5)$. Bars with different superscripts indicate significant differences from each other $(p<0.05)$. 


\section{Mouse sperm analysis}

Effect of S. zonata and S. prophetarum RFs and BFs from the aestivation ecophysiological stage on mouse sperm movement

There were no significant differences $(p>0.05)$ between the effect of fresh RFs obtained from $S$. zonata and $S$. prophetarum, and those stored at $-20^{\circ} \mathrm{C}$ for seven days during the aestivation stage in summer 2014-on thawed mouse sperm (Table 1, Table 2). Accordingly, the percentage of progressive motility (PM) after 30 min of incubation in fresh and stored $S$. prophetarum $\mathrm{RF}$ at $-20^{\circ} \mathrm{C}$ was $0 \%$. During the same period, the PM for the control values was $20 \%, 15 \%, 25 \%$,

Table 1. Thawing mouse-semen parameters in reproductive fluids (RFs) and body fluids (BFs) of S. zonata (a) and S. prophetarum (b) from the aestivation stage.

(a) Semen in fresh Sphincterochila zonata fluids

\begin{tabular}{cccccc}
\hline & \multicolumn{2}{c}{ Motility (\%) } & \multicolumn{2}{c}{ Progressive motility (\%) } & Viability (\%) \\
\hline Samples $*$ time (min) & 0 & $30^{\prime}$ & 0 & $30^{\prime}$ & $30^{\prime}$ \\
1 & $40 ; 30$ & $30 ; 20$ & $40 ; 28$ & $20 ; 15$ & 33 \\
2 & $60 ; 50$ & $25 ; 25$ & $40 ; 30$ & $25 ; 18$ & 30 \\
3 & $50 ; 55$ & $50 ; 40$ & $21 ; 30$ & 0 & 30 \\
4 & $20 ; 24$ & 18,24 & 0 & 0 & 32 \\
\hline
\end{tabular}

(b) Semen in fresh Sphincterochila prophetarum fluids

\begin{tabular}{cccccc}
\hline & \multicolumn{2}{c}{ Motility (\%) } & \multicolumn{2}{c}{ Progressive motility (\%) } & Viability (\%) \\
\hline Samples*/time (min) & 0 & $30^{\prime}$ & 0 & $30^{\prime}$ & $30^{\prime}$ \\
1 & $40 ; 30$ & $30 ; 20$ & $40 ; 28$ & $20 ; 15$ & 33 \\
2 & $60 ; 50$ or $60 ; 30$ & $25 ; 25$ & $40 ; 30$ & $25 ; 18$ & 30 \\
3 & 40,38 & $20 ; 20$ & 0 & 0 & 15 \\
4 & 30,20 & $20 ; 25$ & 0 & 0 & 7
\end{tabular}

*Sperm preparation: 1 -Thawed mouse semen-control 1;2-Thawed mouse semen diluted 1:1 with HAM F-10 - control 2; 3-Thawed mouse semen diluted 1:1 with reproductive fluids; 4 -Thawed mouse semen diluted 1:1 with body fluids.

Table 2. Mouse semen parameters after thawing in reproductive fluids (RFs) and body fluids (BFs) of $S$. zonata and $S$. prophetarum from the aestivation stage in summer 2014.

\begin{tabular}{|c|c|c|c|c|c|c|c|c|c|c|}
\hline \multirow{3}{*}{$\begin{array}{c}\text { Treatment } \\
\text { Time (min) } \\
\text { Snail species }\end{array}$} & \multicolumn{4}{|c|}{ Motility (\%) } & \multicolumn{4}{|c|}{ Progressive motility (\%) } & \multirow{2}{*}{\multicolumn{2}{|c|}{$\begin{array}{c}\text { Viability (\%) } \\
30\end{array}$}} \\
\hline & & 0 & & 30 & & 0 & & 30 & & \\
\hline & $\begin{array}{c}S . \\
\text { zonata }\end{array}$ & $\begin{array}{c}S . \\
\text { prophetarum }\end{array}$ & S. zonata & $\begin{array}{c}S . \\
\text { prophetarum }\end{array}$ & S. zonata & $\begin{array}{c}S . \\
\text { prophetarum }\end{array}$ & S. zonata & $\begin{array}{c}S . \\
\text { prophetarum }\end{array}$ & $\begin{array}{c}S . \\
\text { zonata }\end{array}$ & $\begin{array}{c}S . \\
\text { prophetarum }\end{array}$ \\
\hline Control 1 & $40 ; 30$ & $40 ; 30$ & $30 ; 20$ & $30 ; 20$ & $40 ; 28$ & $40 ; 28$ & $20 ; 15$ & $20 ; 15$ & 33 & 33 \\
\hline Control 2 & $60 ; 50$ & $60 ; 50$ & $25 ; 25$ & $25 ; 25$ & $40 ; 30$ & $40 ; 30$ & $25 ; 18$ & $25 ; 18$ & 30 & 30 \\
\hline${ }^{\star}$ RFs & $45 ; 40$ & $40 ; 25$ & $40 ; 25$ & $25 ; 30$ & $10 ; 18$ & $0 ; 0$ & $0 ; 20$ & $0 ; 0$ & -- & 35 \\
\hline${ }^{\star B F s}$ & $35 ; 30$ & $20 ; 35$ & $27 ; 20$ & $30 ; 30$ & $10 ; 15$ & $10 ; 8$ & $5 ; 0$ & $0 ; 0$ & 18 & 20 \\
\hline
\end{tabular}

Control 1-Thawed mouse semen; Control 2-Mouse semen diluted 1:1 with HAM F-10; RF-Thawed mouse semen diluted 1:1 with RFs; BF-Thawed mouse semen diluted 1:1 with BFs; ${ }^{*}$ Reproductive and body fluids of snails were stored for 7 days at $-20^{\circ} \mathrm{C}$ 
18\% (Table 1, Table 2). In contrast to the decrease in PM, mouse SV exhibited values similar to those of the controls, measured as $30 \%$ for fresh $S$. zonata RF and $35 \%$ after storage (at $-20^{\circ} \mathrm{C}$ ) for $S$. prophetarum $\mathrm{RF}$, while viability of control 1 was $33 \%$ and of control $2 \%-30 \%$. Since there were no significant differences in sperm parameters between fresh and stored (at $\left.-20^{\circ} \mathrm{C}\right) S$. zonata and $S$. prophetarum RFs, we continued testing stored (at $-20^{\circ} \mathrm{C}$ ) $S$. zonata and $S$. prophetarum RFs in winter.

Effect of different S. zonata and S. prophetarum fluids from the active ecophysiological stage on mouse sperm

Figure 4 shows that during the active ecophysiological stage in winter, S. zonata RFs significantly amplified $(p<0.05)$ thawed mouse sperm motility that was 1.34- and 2.02-fold higher than the control medium after 5 and $30 \mathrm{~min}$ of incubation $\left(20^{\circ} \mathrm{C}\right)$, respectively, with values of $55 \%$ and $50.50 \%$ in $S$. zonata RFs compared with $41 \%$ and $25 \%$ for the control treatment, respectively. Like the control treatment, $S$. prophetarum RFs affected mouse sperm motility $(p>0.05)$. Although $S$. zonata BFs increased thawed mouse sperm motility, they did not differ from the control treatment $(p>0.05)$ after both 5 and $30 \mathrm{~min}$ of incubation. $S$. prophetarum BFs had significantly lower values than the control $(p<$ 0.05) (Figure 5).

Figure 6 presents the positive effect of $S$. zonata RFs on mouse sperm PM (43.75\% and $45 \%$ after 5 and 30 min of incubation, respectively), which was significantly higher $(p<0.05)$ than mouse sperm PM incubated in $S$. prophetarum RFs (20\% and $7.5 \%$ after 5 and 30 min of incubation, respectively). Nevertheless, $\mathrm{PM}$ in $S$. zonata RFs was higher than in the control treatment but did not differ significantly $(p>0.05)$. Mouse sperm PM in both $S$. zonata and $S$. prophetarum BFs after $5 \mathrm{~min}(26.67 \% ; 1.0 \%$, respectively) and $30 \mathrm{~min}(11.33 \%$; $1.0 \%$, respectively) incubation was lower than the PM in the control treatment $(40 \% ; 40 \%$, respectively) (Figure 7).

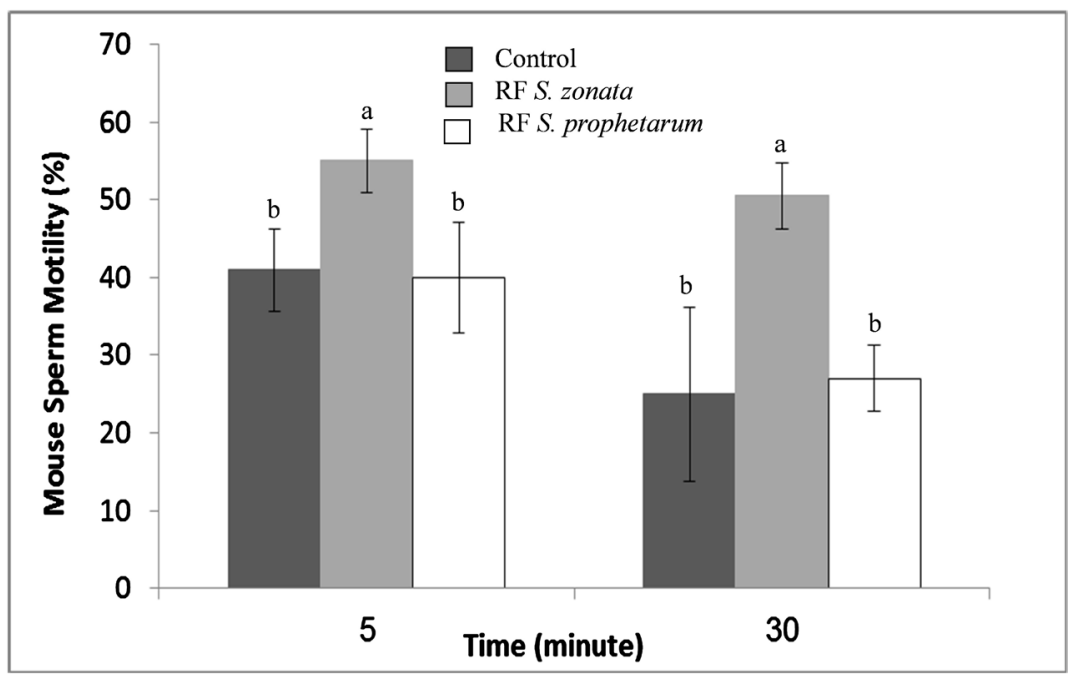

Figure 4. Mean $( \pm \mathrm{SD})$ mouse sperm motility (\%) in the reproductive fluids (RFs) of $S$. zonata and $S$. prophetarum, winter $2014(\mathrm{n}=4)$. 


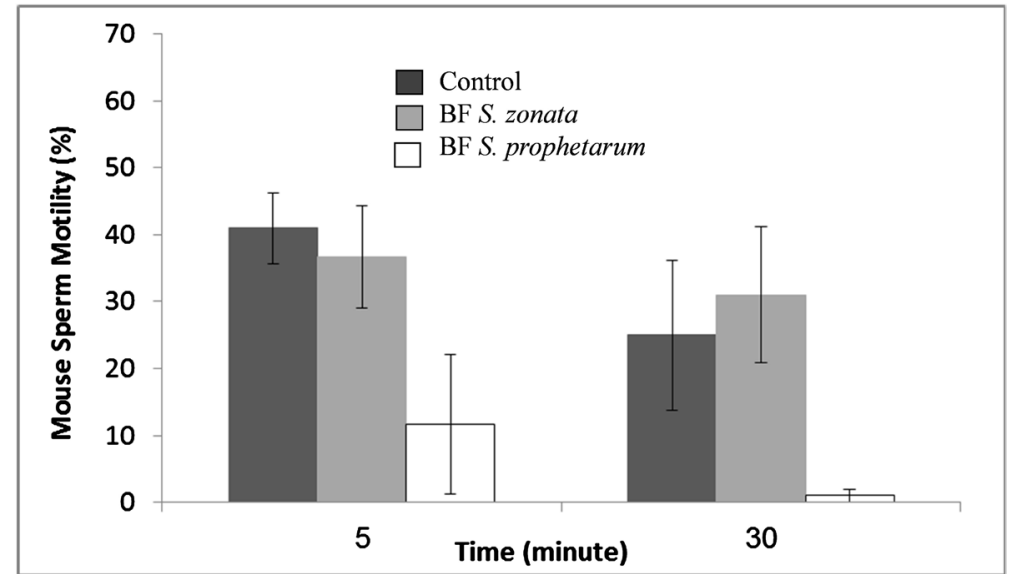

Figure 5. Mean $( \pm \mathrm{SD})$ mouse sperm motility (\%) in body fluids (BFs) of $S$. zonata and $S$. prophetarum, winter $2014(\mathrm{n}=4)$.

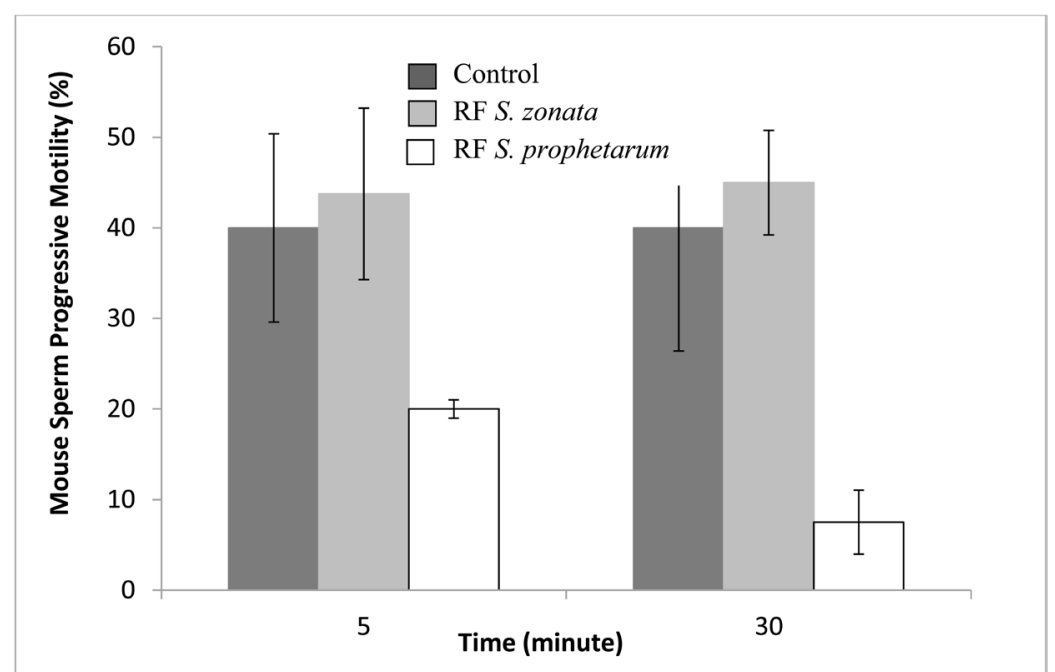

Figure 6. Mean $( \pm \mathrm{SD})$ mouse sperm progressive motility (\%) in reproductive fluids (RFs) of $S$. zonata and $S$. prophetarum, winter $2014(\mathrm{n}=4)$.

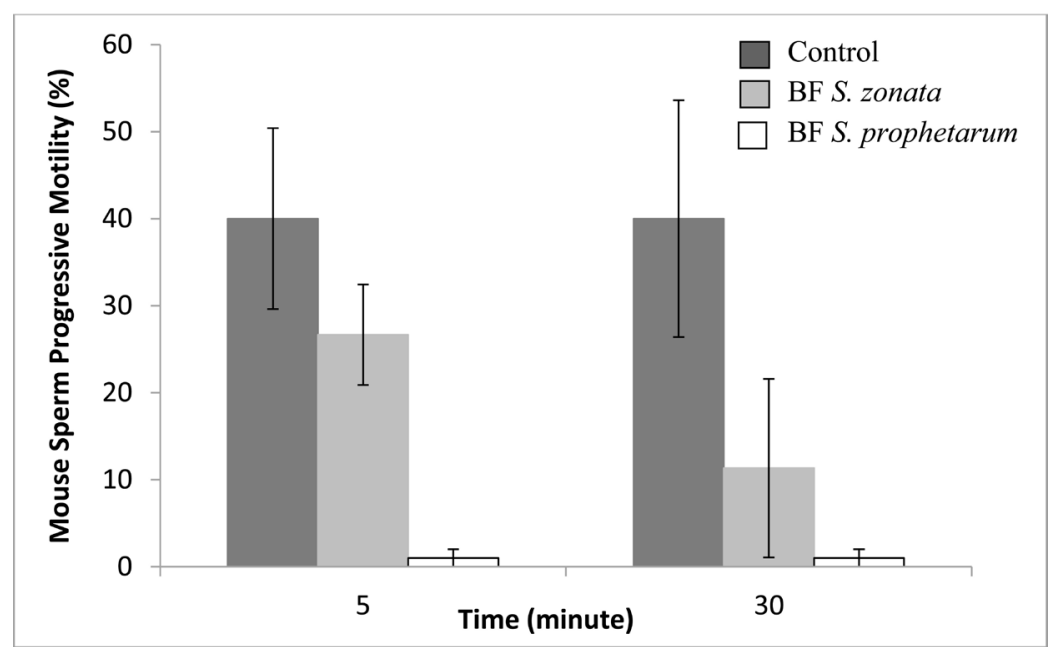

Figure 7. Mean $( \pm \mathrm{SD})$ mouse sperm progressive motility (\%) in body fluids (BFs) of $S$. zonata and $S$. prophetarum, winter $2014(\mathrm{n}=4)$. 
SV was measured after $5 \mathrm{~min}$ of incubation in the control treatment and after 30 min of incubation in both the control and the snail RFs (Table 2). SV in the control treatment decreased from $57 \%$ after 5 min of incubation to $35 \%$ after 30 min of incubation, a value lower than the SV in S. zonata, determined as $43 \%$ $(p>0.05)$. SV in $S$. zonata RFs was significantly higher than SV in $S$. propheta$\operatorname{rum}(31 \%)$ (Table 2).

\section{Discussion}

The search for a better approach for protecting sperm during the cryopreservation process and for improving post-freezing mammalian sperm abilities, such as motility and progressive motility, is ongoing. According to Watson (2000) [9] and Johnson et al. (2000) [27], there are depressing implications for sperm parameters, and only about $50 \%$ of sperm in an ejaculate can survive the thawing procedure. However, many studies present different suggestions [28]. In recent years, several studies have gleaned ideas from nature, for example, Martinez et al. (2017) [29] tested the effect of venom components from the scorpion Scorpio maurus palmatus on mammalian sperm motility, and showed a positive effect on the motility of mouse and fresh human sperm. Kumar et al. (2015) [30] examined the effect of the silk protein sericin on the motility of thawed buffalo sperm. Soleimanzaheh and Saberivand (2013) [31] tested the impact of curcumin on rat sperm morphology after the freeze-thawing process.

Our study shows the potential of using natural RFs of desert snails for preserving and improving the in vitro abilities of thawed mammalian sperm. Preliminary results based on our study [32] indicate that incubated mouse sperm cells in the RFs of $S$. zonata and $S$. prophetarum during the aestivation ecophysiological stage in summer, succeed in maintaining viability on the one hand, while reducing mouse-sperm progressive motility on the other. Moreover, sperm cells in the $S$. zonata RFs obtained in the winter cryptobiosis stage, enabled the maintaining of higher sperm motility, progressive motility, and viability of sperm cells in comparison to RFs obtained in the aestivation stage. In the present study, the snail RFs exhibited a favorable positive response of mouse sperm cells compared with snail BFs or the control treatment. We hypothesized that different proteins existing in $S$. zonata and $S$. prophetarum RFs during the aestivation and active ecophysiological periods were responsible for the thawed-sperm reaction shown in this study. The next step is to identify and isolate the active components of the mouse sperm in the $S$. zonata and $S$. prophetarum RFs. Such a study will enable us to determine the mobility of the live but motionless sperm in summer, along with the increasing PM in winter.

\section{Funding}

This research received no specific grant from any funding agency in the public, commercial, or not-for-profit sectors. 


\section{Authors' Contribution}

All the authors contributed equally through all stages of the study and the writing process.

\section{Acknowledgements}

Special thanks to Mrs. Sharon Victor for her useful comments.

\section{Conflicts of Interest}

The authors declare no conflicts of interest regarding the publication of this paper.

\section{References}

[1] Barbas, J.P. and Mascarenhas, R.D. (2009) Cryopreservation of Domestic Animal Sperm Cells. Cell Tissue Bank, 10, 49-62.

https://doi.org/10.1007/s10561-008-9081-4

[2] Oehninger, S., Duru, N.K., Srisombut, C. and Morshedi, M. (2000) Assessment of Sperm Cryodamage and Strategies to Improve Outcome. Molecular and Cellular Endocrinology, 169, 3-10. https://doi.org/10.1016/S0303-7207(00)00343-9

[3] Yeste, M. (2016) Sperm Cryopreservation Update: Cryodamage, Markers, and Factors Affecting the Sperm Freezability in Pigs. Theriogenology, 85, 47-64. https://doi.org/10.1016/j.theriogenology.2015.09.047

[4] McLaughlin, E.A. (2002) Cryopreservation, Screening and Storage of Sperm-The Challenges for the Twenty-First Century. Human Fertility, 5, S61-S65. https://doi.org/10.1080/1464727022000199941

[5] Han, X. and Critser, J.K. (2016) A Theoretical and Experimental Investigation of Mechanical Damage to Rodent Sperm Generated by Microscale Ice Formation. Cryoletters, 37, 388-393.

[6] Jin, B., Yamasaki, C., Yamada, N., Seki, S., Valdez, D.M., Kasai, M. and Edashige, K. (2008) The Mechanism by Which Mouse Spermatozoa Are Injured during Freezing. Journal of Reproduction and Development, 54, 265-269.

https://doi.org/10.1262/jrd.20056

[7] Low, B.E., Taft, R.A. and Wiles, M.V. (2016) Mouse Sperm Cryopreservation and Recovery of Genetically Modified Mice. In: Proetzel, G. and Wiles, M., Eds., Mouse Models for Drug Discovery, Methods in Molecular Biology, Vol. 1438, Humana Press, New York, 55-66. https://doi.org/10.1007/978-1-4939-3661-8_3

[8] Muldrew, K. and Mcgann, L.E. (1994) The Osmotic Rupture Hypothesis of Intracellular Freezing Injury. Biophysical Journal, 66, 532-541. https://doi.org/10.1016/S0006-3495(94)80806-9

[9] Watson, P.F. (2000) The Causes of Reduced Fertility with Cryopreserved Semen. Animal Reproduction Science, 60, 481-492.

https://doi.org/10.1016/S0378-4320(00)00099-3

[10] O'Connell, M., McClure, N. and Lewis, S.E.M. (2002) The Effects of Cryopreservation on Sperm Morphology, Motility and Mitochondrial Function. Human Reproduction, 17, 704-709. https://doi.org/10.1093/humrep/17.3.704

[11] Alon, G., Shore, L.S. and Steinberger, Y. (2007) Correlation between Levels of Sex Hormones (Progesterone, Testosterone, and Estrogen) and Ecophysiological-Behavior Stages in Two Species of Desert Snails (Sphincterochila zonata and 
Sphincterochila prophetarum) in the Northern Negev Desert. General and Comparative Endocrinology, 151, 122-127. https://doi.org/10.1016/j.ygcen.2006.12.014

[12] Steinberger, Y., Grossman, S. and Dubinsky, Z. (1981) Some Aspects of the Ecology of the Desert Snail Sphincterochila prophetarum in Relation to Energy and Water Flow. Oecologia, 50, 103-108. https://doi.org/10.1007/BF00378801

[13] Steinberger, Y., Grossman, S. and Dubinsky, Z. (1982) Changes in Organic Storage Compounds during the Active and Inactive Periods in a Desert Snail, Sphincterochila prophetarum. Comparative Biochemistry and Physiology, 71, 41-46. https://doi.org/10.1016/0300-9629(82)90364-4

[14] Janer, G. and Porte, C. (2007) Sex Steroids and Potential Mechanisms of Non-Genomic Endocrine Disruption in Invertebrates. Ecotoxicology, 16, 145-160. https://doi.org/10.1007/s10646-006-0110-4

[15] Gottfried, H., Dorfman, R.I. and Wall, P.E. (1967) Steroids of Invertebrates-Production of Oestrogens by an Accessory Reproductive Tissue of Slug Arion ater rufus (Linn). Nature, 215, 409-410. https://doi.org/10.1038/215409a0

[16] Gottfried, H. and Lusis, O. (1966) Steroids of Invertebrates-In Vitro Production of 2-Ketotestosterone and Other Steroids by Eggs of Slug Arion ater rufus (Linn). Nature, 212, 1488-1489. https://doi.org/10.1038/2121488a0

[17] Flari, V.A. and Edwards, J.P. (2003) The Role of the Endocrine System in the Regulation of Reproduction in Terrestrial Pulmonate Gastropods. Invertebrate Reproduction \& Development, 44, 139-161. https://doi.org/10.1080/07924259.2003.9652564

[18] Takeda, N. (1989) Hormonal Control of Reproduction in Land Snails. Venus, 48, 99-139.

[19] Gooding, M.P. and LeBlanc, G.A. (2004) Seasonal Variation in the Regulation of Testosterone Levels in the Eastern Mud Snail (Ilyanassa obsoleta). Invertebrate Biology, 123, 237-243. https://doi.org/10.1111/j.1744-7410.2004.tb00158.x

[20] Hodgson, A.N. and Shachak, M. (1991) The Spermatogenic Cycle and Role of the Hermaphrodite Duct in Sperm Storage in 2 Desert Snails. Invertebrate Reproduction \& Development, 20, 125-136. https://doi.org/10.1080/07924259.1991.9672189

[21] Arad, Z., Goldenberg, S. and Heller, J. (1989) Resistance to Desiccation and Distribution Patterns in the Land Snail Sphincterochila. Journal of Zoology, 218, 353-364. https://doi.org/10.1111/j.1469-7998.1989.tb02549.x

[22] Arad, Z., Mizrahi, T., Goldenberg, S. and Heller, J. (2010) Natural Annual Cycle of Heat Shock Protein Expression in Land Snails: Desert versus Mediterranean Species of Sphincterochila. Journal of Experimental Biology, 213, 3487-3495. https://doi.org/10.1242/jeb.047670

[23] Nevo, E., Barel, C. and Bar, Z. (1983) Genetic Diversity, Climatic Selection and Speciation of Sphincterochila Landsnails in Israel. Biological Journal of the Linnean Society, 19, 339-373. https://doi.org/10.1111/j.1095-8312.1983.tb00792.x

[24] Ben, K., Hamilton, M.S. and Alexander, N.J. (1988) Vasectomy-Induced Autoimmunity: Monoclonal Antibodies Affect Sperm Function and in Vitro Fertilization. Journal of Reproductive Immunology, 13, 73-84. https://doi.org/10.1016/0165-0378(88)90050-2

[25] Johnson, L.A., Weitze, K.F., Fiser, P. and Maxwell, W.M.C. (2000) Storage of Boar Semen. Animal Reproduction Science, 62, 143-172. https://doi.org/10.1016/S0378-4320(00)00157-3

[26] Bjorndahl, L., Soderlund, I. and Kvist, U. (2003) Evaluation of the One-Step Eosin-Nigrosin Staining Technique for Human Sperm Vitality Assessment. Human 
Reproduction, 18, 813-816. https://doi.org/10.1093/humrep/deg199

[27] Tiwari, A., Tekcan, M., Sati, L., Murk, W., Stronk, J. and Huszar, G. (2017) A New Media without Animal Component for Sperm Cryopreservation: Motility and Various Attributes Affecting Paternal Contribution of Sperm. Journal of Assisted Reproduction and Genetics, 34, 647-657. https://doi.org/10.1007/s10815-017-0888-4

[28] World Health Organization (WHO) (2010) Laboratory Manual for the Examination of Human Semen and Sperm-Cervical Mucus Interaction. Cambridge.

[29] Martinez, G., Hograindleur, J.P., Voisin, S., Nahed, R.A., El Aziz, T.M.A., Escoffier, J., Bessonnat, J., Fovet, C.M., De Waard, M., Hennebicq, S., et al. (2017) Spermaurin, an La1-Like Peptide from the Venom of the Scorpion Scorpio maurus Palmatus, Improves Sperm Motility and Fertilization in Different Mammalian Species. Molecular Human Reproduction, 23, 116-131. https://doi.org/10.1093/molehr/gaw075

[30] Kumar, P., Kumar, D., Sikka, P. and Singh, P. (2015) Sericin Supplementation Improves Semen Freezability of Buffalo Bulls by Minimizing Oxidative Stress during Cryopreservation. Animal Reproduction Science, 152, 26-31. https://doi.org/10.1016/j.anireprosci.2014.11.015

[31] Soleimanzadeh, A. and Saberivand, A. (2013) Effect of Curcumin on Rat Sperm Morphology after the Freeze-Thawing Process. Veterinary Research Forum, 4, 185-189.

[32] Hermann, G., Zabludovsky, N. and Steinberger, Y. (2017) A New Approach in the Cryopreservation of Mammalian Sperm Cells to Improve Fertility. FISEB Federation of the Israel Society for Experimental Biology Conference, Eilat, 20-23 February 2017.

\title{
List of Abbreviations
}

\author{
$\mathrm{T}$-Testosterone; \\ E2-17ß estradiol; \\ RFs-Reproductive fluids; \\ BF-Body fluid; \\ SV-Sperm viability.
}

